\title{
Regional Variation in Health Status among Chronic Obstructive Pulmonary Disease Patients
}

\author{
Vincent S. Fan ${ }^{a, b} \quad$ Pierre-Olivier Bridevaux ${ }^{a, c}$ Mary B. McDonell ${ }^{a}$ \\ Stephan D. Fihn ${ }^{a, b}$ Lilah M. Besser ${ }^{a}$ David H. Au ${ }^{a, b}$ \\ ${ }^{a}$ Health Services Research and Development Center of Excellence, VA Puget Sound Health Care System, and \\ ${ }^{b}$ Department of Medicine, University of Washington, Seattle, Wash., USA; ${ }^{C}$ Division of Pulmonary Medicine, \\ University Hospitals of Geneva, Geneva, Switzerland
}

For editorial comment see p. 4

\section{Key Words}

Chronic obstructive pulmonary disease $\cdot$ Lung disease, obstructive $\cdot$ Health-related quality of life $\cdot$ Regional variation $\cdot$ Geographic differences

\begin{abstract}
Background: Little is known about geographic differences in health status among patients with chronic obstructive pulmonary disease (COPD). Objectives: The aim of this study was to examine regional variations in self-reported health status of COPD patients at 7 Veterans Affairs clinics. Methods: The Ambulatory Care Quality Improvement Project was a multicenter, randomized trial conducted from 1997 to 2000 that evaluated a quality improvement intervention in the primary care setting. Four thousand and nine participants with COPD (age $\geq 45$ years) completed the Seattle Obstructive Lung Disease Questionnaire (SOLDQ) and 2,991 also completed the Medical Outcomes Study 36-item short form (SF-36). The unadjusted maximal difference in health status scores is reported as the ratio of the highest and lowest site prevalence. We report the maximal site difference in mean health status scores after adjusting for demographics, comorbidities, utilization, medication use and clinic factors.
\end{abstract}

Results: Subjects were predominantly older $(66.5 \pm 9.2$ years) Caucasian (83.2\%) men (97.9\%). After adjustment, the maximal site difference for each health status score was significant $(p<0.01)$ but larger for the SOLDQ (physical 11.2, emotional 9.7, coping skills 7.6) than for the SF-36 (physical component summary 4.7, mental component summary 2.6). Most of the health status variation was explained by individual or clinic level factors, not clinic site. Conclusions: Our models explained $<30 \%$ of variation in health status measures; therefore, future studies should consider additional predictors of health status such as physical performance, social determinants of health, COPD treatment and environmental factors. Despite its limitations, this study suggests a need to consider regional differences in health status when comparing COPD health outcomes in diverse geographic areas.

Copyright $\odot 2010$ S. Karger AG, Basel

The views expressed in this article are those of the authors and do not necessarily represent the views of the Department of Veterans Affairs or the University of Washington.

V.S.F. and P.-O.B. contributed equally to the manuscript.

\section{KARGER}

Fax +41613061234 E-Mail karger@karger.ch www.karger.com (c) 2010 S. Karger AG, Basel

0025-7931/11/0811-0009\$38.00/0

Accessible online at:

www.karger.com/res
Vincent S. Fan, MD, MPH

VA Puget Sound Health Care System

1100 Olive Way, Suite 1400

Seattle, WA 98101 (USA)

Tel. +1 206764 2504, Fax +1 206764 2935, E-Mail vincent.fan@va.gov 


\section{Introduction}

Chronic obstructive pulmonary disease (COPD) affects approximately 19 million Americans, is the underlying cause in 1 in 20 deaths in the United States (US) and is expected to increase in prevalence in the future $[1,2]$. COPD has a large detrimental effect on functional status and perceived, self-reported health status and is predicted to be the 6th leading cause of disability-adjusted life years by 2020 [3]. Health status of patients with COPD has been demonstrated to predict important health outcomes including hospitalizations and all-cause mortality, independent of pulmonary function as measured by forced expiratory volume [4-8].

Previous studies in the US and the United Kingdom have suggested that there are regional variations in functional status among the elderly that are independent of sociodemographic characteristics, lifestyle characteristics and chronic medical conditions $[9,10]$. Regional variations in health status among veterans [11] have been demonstrated to be independent of coexisting illnesses, certain health behaviors such as tobacco use and sociodemographic characteristics [12]. Geographic variations in medical care have been demonstrated among patients with COPD [13] and other conditions [14] and have been suggested as an important predictor of COPD exacerbation rates [15]. Altogether, these studies suggest that variation in care delivery may account for regional variation in health status. We sought to characterize the health status among patients with self-reported chronic lung disease from a large outpatient population in the US and to compare the health status between 7 geographically diverse sites within the same integrated health care system, while adjusting for sociodemographics, comorbidity, utilization, medication use and clinic factors.

\section{Materials and Methods}

\section{Patients, Data and Survey Collection}

Our study population was identified from patients receiving regular primary care from 1 of 7 Veterans Affairs (VA) General Internal Medicine Clinics (West Los Angeles, Calif.; San Francisco, Calif.; Seattle, Wash.; White River Junction, Vt.; Richmond, Va.; Little Rock, Ark.; Birmingham, Ala., USA) participating in the Ambulatory Care Quality Improvement Project (ACQUIP) from 1997 to 2000 [16]. In brief, ACQUIP was a multicenter, randomized trial that evaluated a quality improvement intervention in the primary care setting. Data on self-reported health status, medication use, inpatient and outpatient health care utilization, as well as sociodemographic variables were collected during the study period. ACQUIP patients were first sent a screening health inventory that included 24 common chronic medical conditions. If patients reported 'chronic lung disease, emphysema, asthma or bronchitis', they were mailed a condition-specific questionnaire, the Seattle Obstructive Lung Disease Questionnaire (SOLDQ), and the Medical Outcomes Study 36-item short form (SF-36), a general health status questionnaire.

Our analysis included patients who had a confirmed International Classification of Disease (ICD)-9 diagnosis (in- or outpatient; 491.x, 492.x or 496.x) of COPD and returned the SOLDQ within a year of returning the initial mailed health inventory. Patients $<45$ years were excluded to reduce misclassification of asthma patients. This study protocol was approved by the Human Subjects Committee of the University of Washington.

\section{Health Status Questionnaires}

The main outcomes of interest were regional differences in health status among COPD patients, as measured with the SOLDQ and SF-36. The SOLDQ is a valid and reliable self-administered questionnaire designed to assess the health status of COPD patients [17] and consists of 29 items summarized into 3 health domains and a satisfaction domain (scored from 0 to 100; 100 represents perfect health). The physical function domain assesses the degree of dyspnea and physical limitation, the emotional function domain assesses the effect of COPD on psychological well-being, and the coping skills domain reflects patients' convictions regarding their ability to cope with pulmonary disease. The SOLDQ has been shown to predict hospitalizations and death among patients with COPD [5], and the minimal clinically important difference is approximately 5 points [17].

The SF-36 has been validated and extensively used to measure the general health status of patients, including those with COPD [18-20]. Two summary scales of the SF-36, the physical component summary (PCS) and the mental component summary (MCS), have been developed to measure general physical and mental health. The summary scales are standardized to a population mean of 50 and a standard deviation of 10 [21].

\section{Potential Explanatory Variables}

Sociodemographic information was collected in the mailed survey and supplemented by the VA computerized medical record system (VistA); it includes: age, gender, income, education level, marital status, ethnicity and smoking status.

Comorbidities were assessed with both administrative data and self-report. We calculated the Charlson index, a comorbidity index developed to predict mortality, using both inpatient and outpatient diagnosis codes for the 1-year baseline period $[22,23]$. Because comorbidity indexes developed to predict mortality may not predict health status well, we also included 9 selfreported conditions previously shown to predict health status (arthritis, osteoporosis, stroke, angina, diabetes, congestive heart failure, heart attack, stomach ulcer and depression) [24], as well as 3 additional self-reported conditions (cancer, kidney disease and pneumonia) associated $(\mathrm{p}<0.10)$ with the SOLDQ and SF-36. A count of these 12 self-reported comorbidities was used to generate a self-reported comorbidity score. Both the Charlson and self-reported comorbidity scores were included in the final model.

A number of variables were used as proxy measures of COPD disease severity. First, we assessed the number of hospitalizations with a primary discharge diagnosis of COPD over a 1-year period 
$[5,25]$. Additionally, the frequency of COPD exacerbations was defined by the number of outpatient ICD-9 codes for COPD and a new prescription for prednisone or antibiotics. Finally, COPD medication use was assessed using pharmacy records from each site for the year following the self-report of chronic lung disease and included bronchodilators ( $\beta_{2}$-agonists, ipratropium bromide, theophylline), inhaled corticosteroids and chronic oral corticosteroid use (defined as sufficient prescriptions to use steroids $>50 \%$ of days over a 1 -year period). Patients who filled 1 or more prescriptions were considered users.

\section{Clinic Factors}

All patients were assigned to a primary care provider during the study period. The following provider characteristics were obtained as part of the ACQUIP trial: (1) provider training (staff physician, resident/fellow, or nurse practitioner/physician assistant), (2) provider gender, and (3) average panel size (number of patients) during the study. Provider age was not collected. We also included self-reported data on whether subjects received non-VA care, and the patient's number of primary care visits based on administrative data.

\section{Statistical Analysis}

Respondents and nonrespondents meeting our inclusion criteria (age $\geq 45$ years, ICD-9 confirmed self-reported COPD) were compared for each of the categorical and continuous variables using $\chi^{2}$ tests and one-way ANOVA, respectively. Similarly, we tested for significant regional differences for each of the respondents' characteristics. Unadjusted maximal differences by site are reported as a ratio of the highest to the lowest site prevalence $(\mathrm{H} / \mathrm{L}$ ratio).

Multivariate linear regression models were constructed to predict the scores on the 3 SOLDQ domains (physical function, emotional function, coping skills) and the 2 SF-36 scales (PCS and MCS). The site with the highest score was the reference site for statistical comparisons for each domain or scale. We a priori created 5 separate sets of potential explanatory variables (sociodemographics, comorbidity, COPD utilization, COPD medications and clinic factors), which were added to the unadjusted models en bloc in the following order: (1) sociodemographics and comorbidity, (2) plus COPD utilization, (3) plus medications, (4) plus clinic factors. We report the adjusted maximal differences $(\Delta \max )$ in mean health status scores between sites with the lowest and highest values. Standard errors were determined using robust estimates of variance clustering by provider to account for correlation between observations.

Finally, we quantified the variance $\left(\mathrm{R}^{2}\right)$ in health status domains/scales explained separately by the previously defined sets of explanatory factors, and also the variance when all variables were in the same model with and without site. All analyses were performed using STATA (College Station, Tex., USA).

\section{Results}

Of the 33,358 patients 45 years or older who returned the screening health inventory, 8,337 (25.0\%) reported lung disease and 5,496 (65.9\%) also had a confirmatory
ICD-9 discharge diagnosis of COPD. Of the patients with confirmed COPD, 4,009 patients (72.9\%) returned the SOLDQ and 2,991 (54.4\%) also returned the SF-36. Compared with nonrespondents, respondents to the SOLDQ were slightly older (66.5 vs. 65.5 years; $\mathrm{p}=0.0003)$, more likely to be Caucasian ( 83.2 vs. $76.8 \%$; p $<0.0001$ ), married (60.6 vs. $51.2 \%$; $<<0.0001)$, finished high school (61.1 vs. $57.9 \%$; $\mathrm{p}=0.042)$, and less likely to be a current smoker (32.0 vs. $40.6 \%$; $\mathrm{p}<0.0001)$.

Among the 4,009 respondents, most were male (97.9\%) and current $(32.0 \%)$ or past $(61.5 \%)$ smokers (table 1$)$. There were significant regional differences by demographic factors, with the largest difference in the proportion of patients with less than a high school education (19.3\% in San Francisco, 47.7\% in White River Junction, $\mathrm{H} / \mathrm{L}$ ratio $2.6 ; \mathrm{p}<0.01)$. There was a small but significant regional difference in the self-reported comorbidity score $(\mathrm{H} / \mathrm{L}$ ratio $1.3 ; \mathrm{p}<0.01)$. Significant regional differences were observed for COPD disease severity, particularly for the proportion of patients with $\geq 1$ pulmonary clinic visit $(\mathrm{H} / \mathrm{L}$ ratio $3.1 ; \mathrm{p}<0.01)$. A difference in medication use by site was also seen with the largest difference in theophylline use $(\mathrm{H} / \mathrm{L}$ ratio $3.4 ; \mathrm{p}<0.01)$ and chronic prednisone therapy $(\mathrm{H} / \mathrm{L}$ ratio $4.8 ; \mathrm{p}=0.1)$.

There were significant regional differences in provider characteristics among respondents (data not shown), including differences in the proportion of resident physicians (13.8\% in Little Rock, 77.5\% in Birmingham, H/L ratio $5.6 ; \mathrm{p}<0.0001)$. There was also variability in male providers (32.6\% in Birmingham, 59.4\% in Little Rock, $\mathrm{H} / \mathrm{L}$ ratio $1.8 ; \mathrm{p}<0.0001)$ and mean panel size (126.2 in Seattle, 775.4 in Little Rock, H/L ratio 6.1; $\mathrm{p}<0.0001$ ). Over a third of the patients used non-VA care and this differed significantly by site $(\mathrm{H} / \mathrm{L}$ ratio $1.5 ; \mathrm{p}<0.01)$.

In the unadjusted analyses, we found large and significant regional variations $(p<0.0001)$ in all domains of the SOLDQ and SF-36 (fig. 1). COPD subjects reported marked physical impairment with a mean physical function domain score of $36.7 \pm 22.3(\mathrm{H} / \mathrm{L}$ ratio 1.5$)$ (table 2$)$. Patients had mean scores of $57.1 \pm 25.0(\mathrm{H} / \mathrm{L}$ ratio 1.3$)$ for the emotional function domain and $63.6 \pm 23.9(\mathrm{H} / \mathrm{L}$ ratio 1.2) for the coping skills domain. Among patients also completing the SF-36, the mean scores were $28.0 \pm$ 9.5 (H/L ratio 1.3) for the PCS and $44.1 \pm 13.1(\mathrm{H} / \mathrm{L}$ ratio 1.1) for the MCS.

After adjustment for potential explanatory factors, large and clinically meaningful differences by site were seen for the physical function $(\Delta \max 11.2 ; \mathrm{p}<0.0001)$, emotional function $(\Delta \max 9.7 ; \mathrm{p}<0.0001)$ and coping skills $(\Delta \max 7.6 ; \mathrm{p}<0.0001)$ domains of the SOLDQ, as 
Table 1. Baseline characteristics for respondents to the SOLDQ

\begin{tabular}{|c|c|c|c|c|c|c|c|c|c|c|}
\hline & \multirow{2}{*}{$\begin{array}{l}\text { All sites } \\
(\mathrm{n}=4,009)\end{array}$} & \multirow{2}{*}{$\begin{array}{l}\mathrm{H} / \mathrm{L} \\
\text { ratio }\end{array}$} & \multicolumn{7}{|c|}{ General internal medicine clinics } & \multirow{2}{*}{$\begin{array}{l}\mathrm{p} \\
\text { value }\end{array}$} \\
\hline & & & $\begin{array}{l}\text { White River } \\
\text { Junction, Vt. } \\
(\mathrm{n}=615)\end{array}$ & $\begin{array}{l}\text { Birmingham } \\
\text { Ala. } \\
(\mathrm{n}=596)\end{array}$ & $\begin{array}{l}\text { Little Rock } \\
\text { Ark. } \\
(\mathrm{n}=1,024)\end{array}$ & $\begin{array}{l}\text { Richmond } \\
\text { Va. } \\
(\mathrm{n}=502)\end{array}$ & $\begin{array}{l}\text { San } \\
\text { Francisco } \\
\text { Calif. } \\
(\mathrm{n}=282)\end{array}$ & $\begin{array}{l}\text { Seattle } \\
\text { Wash. } \\
(\mathrm{n}=752)\end{array}$ & $\begin{array}{l}\text { West Los } \\
\text { Angeles } \\
\text { Calif. } \\
(\mathrm{n}=238)\end{array}$ & \\
\hline \multicolumn{11}{|l|}{ Sociodemographics } \\
\hline Mean age $\pm S D$, years & $66.5 \pm 9.2$ & 1.0 & $68.3 \pm 8.8$ & $65.4 \pm 8.9$ & $65.7 \pm 9.4$ & $66.0 \pm 8.8$ & $67.5 \pm 9.5$ & $67.2 \pm 9.3$ & $66.2 \pm 9.5$ & $<0.01$ \\
\hline Male gender, $\%$ & 97.9 & 1.0 & 98.9 & 97.1 & 98.5 & 98.4 & 98.2 & 97.6 & 94.5 & $<0.01$ \\
\hline Education $<$ HS graduate ${ }^{1}, \%$ & 38.9 & 2.6 & 47.7 & 44.1 & 42.9 & 50.4 & 19.3 & 27.0 & 23.2 & $<0.01$ \\
\hline Income $<$ USD $10,000^{2}, \%$ & 30.7 & 2.1 & 25.1 & 32.1 & 28.9 & 29.4 & 27.2 & 31.7 & 52.6 & $<0.01$ \\
\hline Caucasian, \% & 83.2 & 1.6 & 87.0 & 78.0 & 89.4 & 75.5 & 78.4 & 91.0 & 57.6 & $<0.01$ \\
\hline Current smoker, $\%$ & 32.0 & 1.4 & 24.7 & 34.3 & 35.1 & 31.6 & 27.6 & 34.1 & 30.5 & $<0.01$ \\
\hline \multicolumn{11}{|l|}{ Comorbidity } \\
\hline Mean Charlson score \pm SD & $1.1 \pm 1.6$ & 1.2 & $1.0 \pm 1.5$ & $1.2 \pm 1.8$ & $1.1 \pm 1.6$ & $1.2 \pm 1.7$ & $1.0 \pm 1.6$ & $1.2 \pm 1.6$ & $1.2 \pm 1.4$ & 0.5 \\
\hline Mean self-report score ${ }^{3} \pm S D$ & $2.8 \pm 2.0$ & 1.3 & $2.6 \pm 1.9$ & $3.2 \pm 2.2$ & $3.1 \pm 2.0$ & $2.9 \pm 2.1$ & $2.5 \pm 1.8$ & $2.8 \pm 1.8$ & $2.4 \pm 1.7$ & $<0.01$ \\
\hline \multicolumn{11}{|l|}{ COPD disease severity } \\
\hline \multicolumn{11}{|l|}{ Health care utilization, $\%$} \\
\hline$\geq 1$ COPD hospitalization & 20.4 & 1.6 & 22.8 & 23.3 & 18.2 & 22.9 & 14.9 & 20.1 & 18.1 & 0.011 \\
\hline$\geq 1$ COPD exacerbation & 7.7 & 2.0 & 5.4 & 9.1 & 7.7 & 10.2 & 8.9 & 7.1 & 5.0 & 0.03 \\
\hline$\geq 1$ pulmonary clinic visit & 20.2 & 3.1 & 16.6 & 10.2 & 15.5 & 19.5 & 28.0 & 32.1 & 29.4 & $<0.01$ \\
\hline \multicolumn{11}{|l|}{ Mean outpatient visits \pm SD } \\
\hline All visits & $4.2 \pm 4.0$ & 2.0 & $2.7 \pm 1.9$ & $4.5 \pm 3.5$ & $3.8 \pm 3.4$ & $4.0 \pm 2.6$ & $5.4 \pm 4.8$ & $5.2 \pm 5.2$ & $4.9 \pm 6.3$ & $<0.01$ \\
\hline COPD related & $1.9 \pm 2.6$ & 1.7 & $1.9 \pm 2.6$ & $1.7 \pm 2.3$ & $1.6 \pm 2.0$ & $1.8 \pm 2.3$ & $2.7 \pm 3.4$ & $2.0 \pm 3.3$ & $1.9 \pm 2.6$ & $<0.01$ \\
\hline Non-VA care, $\%$ & 36.4 & 1.5 & 42.6 & 37.7 & 34.9 & 35.8 & 35.1 & 36.0 & 27.6 & $<0.01$ \\
\hline \multicolumn{11}{|l|}{ COPD medication use, $\%$} \\
\hline$\beta_{2}$-Agonists & 65.1 & 1.2 & 69.1 & 69.1 & 59.8 & 66.1 & 64.9 & 68.2 & 55.9 & $<0.01$ \\
\hline Ipratropium bromide & 47.2 & 1.8 & 51.1 & 66.3 & 36.2 & 48.0 & 49.7 & 45.4 & 38.2 & $<0.01$ \\
\hline Inhaled steroids & 35.2 & 1.7 & 44.4 & 36.9 & 29.6 & 39.6 & 33.0 & 34.4 & 26.1 & $<0.01$ \\
\hline Theophylline & 20.0 & 3.4 & 23.1 & 27.7 & 19.7 & 25.5 & 8.2 & 16.8 & 6.7 & $<0.01$ \\
\hline Chronic steroid use & 4.7 & 4.8 & 6.3 & 4.4 & 4.9 & 4.2 & 3.9 & 5.1 & 1.3 & 0.10 \\
\hline
\end{tabular}

well as for the PCS $(\Delta \max 4.7 ; \mathrm{p}<0.0001)$ and MCS $(\Delta \max 2.6 ; \mathrm{p}=0.002)$ of the SF-36. Adjusting for sociodemographics and comorbidity had the largest impact on the unadjusted $\Delta$ max for each SOLDQ domain and SF-36 scale; additionally adjusting for clinic factors did not substantially change the results.

Comorbidity explained the most variation for both the SF-36 and SOLDQ scores, whereas COPD disease severity (COPD utilization and medications) explained the most variation in each of the SOLDQ domains but less of the SF-36 scores (table 3). While clinic factors explained only $0.3-1.5 \%$ of the variance in the health status scores, comorbidity explained $6.8-22.9 \%$ of health status scores. Site was a better predictor of variability in physical compared with psychological scores for both questionnaires. When all potential explanatory variables were included in the model excluding site, these variables explained only $19-29 \%$ of the variability in SOLDQ and SF-36 scores. Although statistically significant, adding site only slightly increased the amount of SOLDQ/SF-36 score variability explained.

\section{Discussion}

The perceived health status of veterans with chronic lung disease in this study was substantially worse than that documented for Veterans from past studies [12, 26], reflecting the detrimental effects of COPD on health status $[27,28]$. We observed significant regional variations in health status among COPD patients, particularly for the physical health domains. Although health care utilization, medication use and comorbidity contributed the most to explaining variability in health status, including all potentially explanatory variables, they accounted for $<30 \%$ of the variance in health status scores. 


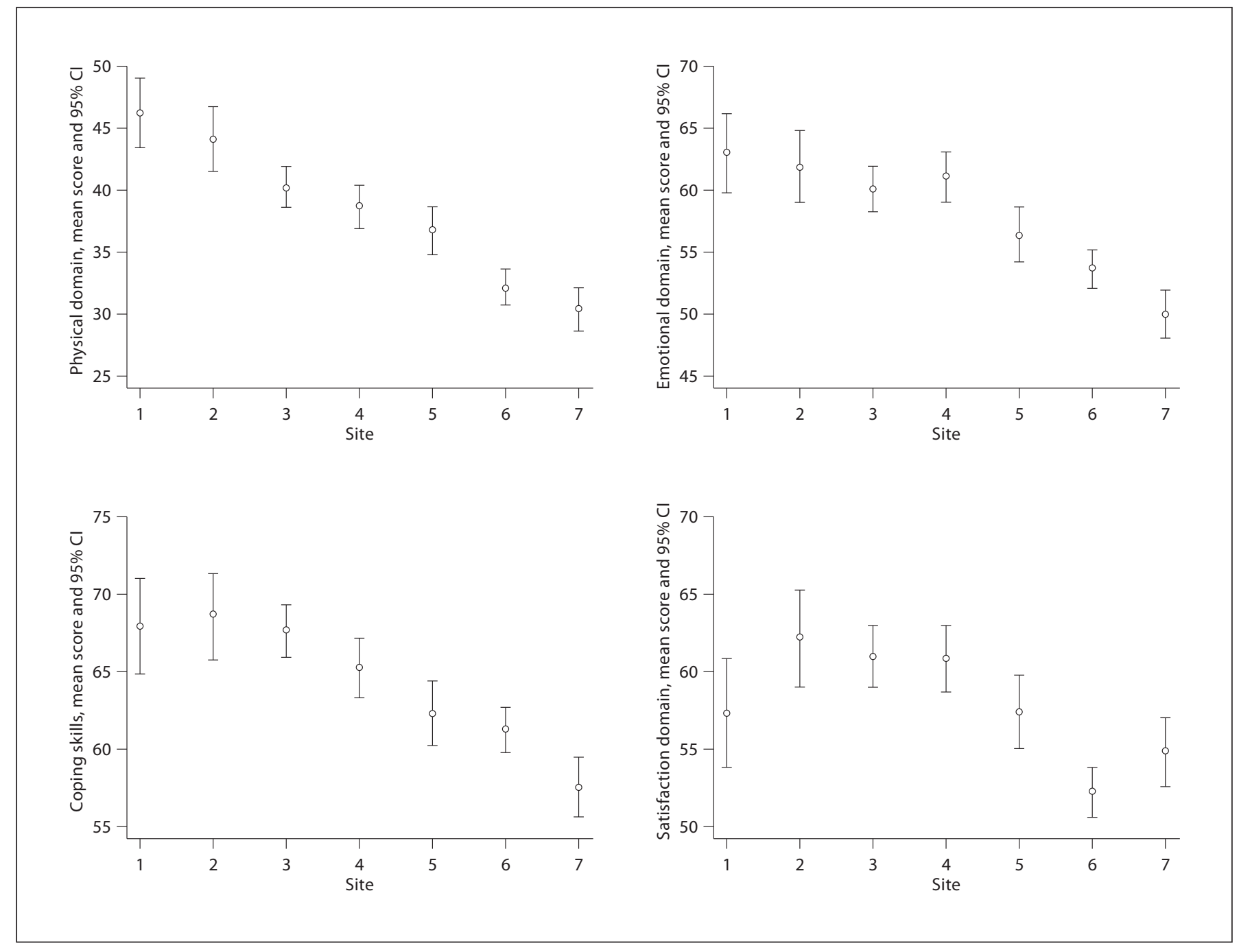

Fig. 1. Regional differences in mean SOLDQ scores among veterans with COPD. 1 = West Los Angeles, Calif.; 2 = San Francisco, Calif.; 3 = Seattle, Wash.; 4 = White River Junction, Vt.; 5 = Richmond, Va.; 6 = Little Rock, Ark.; 7 = Birmingham, Ala. $\mathrm{p}<0.00001$ for differences by site for all 4 SOLDQ domains.

We included several factors that could contribute to regional differences in health status including COPD disease severity, medications used to treat COPD, sociodemographic variables, comorbid illness and factors related to the providers caring for COPD patients. However, adjusting for measures of COPD disease severity did not fully explain the variance in health status scores. We also found that sites with the best health status tended to have the lowest proportion of patients taking inhaled medications (data not shown). This pattern is consistent with COPD guidelines that recommend increasing medication use based on increasing symptom burden. Clinic factors explained very little of health status variation and had little impact on the adjusted maximal differences in health status by site.

In spite of extensive self-reported data combined with administrative and pharmacy data, our models only explained up to $29 \%$ of SOLDQ and SF-36 score variability, indicating that health status is mostly predicted by other variables not measured in this study. Variation in these unmeasured variables by site might have led to the observed regional differences in health status. We used several measures to assess disease severity including the number of COPD-related exacerbations, hospitalizations and clinic visits as well as clinic visits to a pulmonary specialist. However, objective measures of disease severity 
Table 2. $\Delta \max$ in mean health status scores between sites

\begin{tabular}{llllllll}
\hline $\begin{array}{l}\text { Health status } \\
\text { measure } \\
(\mathrm{n}=4,009)\end{array}$ & $\begin{array}{l}\text { Mean } \\
\text { score } \pm \text { SD }\end{array}$ & $\begin{array}{l}\mathrm{H} / \mathrm{L} \\
\text { ratio }\end{array}$ & $\begin{array}{l}\text { Model 1 } \\
\text { unadj. difference } \\
\text { between sites } \\
\Delta \max \end{array}$ & $\begin{array}{l}\text { Model 2 } \\
\text { adj. for SES and } \\
\text { comorbidity } \\
\Delta \max \end{array}$ & $\begin{array}{l}\text { Model 3 } \\
\text { adj. for SES, comor- } \\
\text { bidity and COPD } \\
\text { utilization, } \Delta \max \end{array}$ & $\begin{array}{l}\text { Model 4 } \\
\text { adj. for SES, comorbidity, } \\
\text { COPD utilization and } \\
\text { medications, } \Delta \text { max }\end{array}$ & $\begin{array}{l}\text { Model 5 } \\
\text { adj. for SES, comorbidity, } \\
\text { COPD utilization and medica- } \\
\text { tions, and clinic factors, } \Delta \text { max }\end{array}$ \\
\hline $\begin{array}{l}\text { SOLDQ } \\
\quad \text { Physical }\end{array}$ & $36.7 \pm 22.3$ & 1.5 & 15.9 & 11.3 & 11.6 & 10.3 & 11.2 \\
$\quad \begin{array}{l}\text { Emotional } \\
\text { Coping skills }\end{array}$ & $57.1 \pm 25.0$ & 1.3 & 13.1 & 10.5 & 9.4 & 8.5 & 9.7 \\
SF-36 (n=2,991) & $63.6 \pm 23.9$ & 1.2 & 11.1 & 8.8 & 8.4 & 6.7 & 7.6 \\
$\quad$ PCS & $28.0 \pm 9.5$ & 1.3 & 7.1 & 4.7 & 5.0 & 4.9 & 4.7 \\
$\quad$ MCS & $44.1 \pm 13.1$ & 1.1 & 4.8 & 3.3 & 3.3 & 3.2 & 2.6 \\
\hline
\end{tabular}

Adj. = Adjusted; SES = sociodemographics. All $\mathrm{p}$ values for difference in sites $<0.01$. Model 2 adjusted for: age, marital status, ethnicity, education level, income, smoking status, Charlson and self-reported comorbidity scores. Model 3 adjusted for: variables in model 2 and $\geq 1$ COPD hospitalization, $\geq 1$ COPD exacerbation, $\geq 1$ pulmonary clinic visit, number of COPD-related clinic visits.
Model 4 adjusted for: variables in model 3 and prescriptions for $\beta_{2}$-agonists, ipratropium, combined (ipratropium $+\beta_{2}$-agonists), theophylline, inhaled corticosteroids and chronic oral steroids. Model 5 adjusted for: variables in model 4 and primary care provider type, gender and panel size, number of primary care visits and use of non-VA care.

Table 3. Variance in health status score $\left(\mathrm{R}^{2}, \%\right)$ explained by geographic site, sociodemographics, comorbidity, COPD utilization and medications, and clinic characteristics

\begin{tabular}{|c|c|c|c|c|c|c|c|c|}
\hline $\begin{array}{l}\text { Health status } \\
\text { measure }\end{array}$ & Site & SES & Comorbidity & $\begin{array}{l}\text { COPD } \\
\text { utilization }\end{array}$ & $\begin{array}{l}\text { COPD } \\
\text { medications }\end{array}$ & $\begin{array}{l}\text { Clinic } \\
\text { factors }\end{array}$ & $\begin{array}{l}\text { Final model } \\
\text { without site }\end{array}$ & $\begin{array}{l}\text { Final model } \\
\text { with site* }\end{array}$ \\
\hline \multicolumn{9}{|l|}{ SOLDQ } \\
\hline Physical & 4.5 & 4.6 & 9.7 & 5.5 & 6.2 & 0.9 & 22.9 & 24.9 \\
\hline Emotional & 3.0 & 4.0 & 8.3 & 3.4 & 4.8 & 0.4 & 19.4 & 21.1 \\
\hline Coping skills & 2.4 & 4.4 & 6.8 & 3.7 & 4.5 & 0.3 & 18.2 & 19.4 \\
\hline \multicolumn{9}{|l|}{ SF-36 } \\
\hline PCS & 5.5 & 3.9 & 11.2 & 3.7 & 3.4 & 1.5 & 20.1 & 21.9 \\
\hline MCS & 1.7 & 7.1 & 22.9 & 0.3 & 0.3 & 0.5 & 28.6 & 29.3 \\
\hline
\end{tabular}

SES = Sociodemographics. SES variables: age, marital status, ethnicity, education level, income, smoking status. Comorbidity variables: Charlson score and self-reported comorbidity score. COPD utilization variables: $\geq 1$ COPD hospitalization, $\geq 1$ COPD exacerbation, $\geq 1$ pulmonary clinic visit, number of COPD-related clinic visits. COPD medication variables: prescriptions for $\beta_{2}$-agonists, ipratropium, combined (ipratropium $+\beta_{2}$-agonists), the- ophylline, inhaled corticosteroids and chronic oral steroids. Clinic factors: primary care provider type, gender and panel size, number of primary care visits and use of non-VA care. Final model: SES, comorbidity, COPD utilization, COPD medications and clinic variables combined.

${ }^{*}$ p value for addition of site to final model $<0.001$ for all health status scales. such as spirometry and physical performance were not able to be measured in this dataset. Measures of physical performance such as the 6- or 12-min walk test $[29,30]$ are associated with health status, and regional differences in physical performance may in part account the variability between sites. In addition, although we adjusted for self-reported history of depression, both anxiety and depressive symptoms may also contribute to perceived health status.
Along with unmeasured components of disease severity and comorbidity, other individual factors may better predict health status and its regional variation, such as differences in the environment, patient health behaviors (e.g., diet, exercise, medication compliance) and family support. In addition, patient perception of health status and differences in perception by site may not have been captured in our analysis and within the sociodemographic variables [31]. Clinic characteristics (e.g., provider 
training or non-VA care) explained $<1 \%$ of the variance in SOLDQ scores; however, unmeasured clinic factors such as practice patterns, availability of pulmonary rehabilitation or self-management programs, provider age, or quality of care might better explain health status and its regional variation. While differences in treatment types such as pulmonary rehabilitation could also help predict health status, the number of patients who participate in such programs is small, and the overall effect on health status would likely be small $[32,33]$. Finally, performance measures such as vaccination rates, inhaler education or appropriate, guideline-based use of medications were not available and might explain regional differences in health status.

A prior study of regional variation in health status among veterans followed in the general medicine clinic found that differences in health status were largely accounted for by comorbidity and sociodemographic factors [12]. In this study, we included only patients with COPD and examined variation in both a disease-specific (SOLDQ) and generic (SF-36) measure of health status. We found that COPD-specific measures of disease severity such as health care utilization and COPD treatment explained as much variance in SOLDQ scores as sociodemographic factors. The clinic site accounted for an additional $2 \%$ of the variance in the final model that was not explained by other factors.

Our study has several strengths. We sampled a large clinic-based cohort of veterans with COPD, with diagnoses confirmed by patients and their providers representing 7 different geographic regions of the US. Moreover, we had extensive data from patients and administrative records on comorbid conditions, as well as comprehensive pharmacy and administrative data to assess multiple measures of disease severity and treatment of COPD. We had complete data on VA inpatient and outpatient resource utilization and on filled prescriptions (veterans fill $98 \%$ of their medications through the VA) [34]. Finally, we used 2 well-validated measures of health status.

Our study has some potential limitations. The diagnosis and severity of COPD could not be verified by pulmonary function testing. To limit misclassification of COPD and asthma, we restricted the analysis to patients $>45$ years and to those with both self-reported diagnosis of chronic lung disease and a provider ICD-9 code for COPD. Although the older age of the cohort and the high prevalence of smoking history should help minimize the inclusion of patients with asthma patients who are known to have a better health status $[35,36]$, misclassification may still have occurred. In order to affect our results, COPD would have to be differentially diagnosed or misclassified between sites. The possibility remains that a portion of the regional variation in health status is attributable not only in identifying COPD, but also in incomplete adjustment based on the variables that were available.

Although less likely, our results could reflect systematic selection bias of patients with more severe disease at certain sites. Geographic variation due to impaired access to health care may contribute to differences in health status; however, VA medical centers are available to all eligible veterans regardless of their ability to pay for services. Also, we were not able to adjust for exposure to outdoor air pollution, which is associated with risk of hospitalizations [37-39] and emergency department [40] visits and may contribute to a variation in health status among COPD. Patients completed the questionnaires at home and were not asked regarding COPD clinical stability. Since only $8 \%$ were treated for an exacerbation over a 1 -year period, it is unlikely that many patients were experiencing an exacerbation when completing the survey. Additionally, our results might have been affected by nonresponse, but our comparison of respondents and nonrespondents suggests minimal differences. Finally, our results may not be generalizable beyond this sample of patients [41]. Given these limitations, the results of the study should be interpreted carefully, and further study is needed to better understand the factors associated with geographic variation in health status for patients with COPD.

In conclusion, our results suggest clinically significant regional differences in health status [42] among a large population of COPD patients. The majority of clinical efficacy trials are multicentered and often utilize health status instruments to measure efficacy [43-45]. Some have advocated that health status, not airflow decline, should be the primary measure of clinical effect among COPD patients. Health status assessment has also been suggested a possible performance measure in evaluating systems of care. Our findings suggest that study designs and analyses of clinical trials might need to consider regional differences in health status. In this study, extensive survey information combined with administrative data on health care utilization and medication use explained less than $30 \%$ of the variance in health status scores, suggesting that factors that may explain health status such as unmeasured social determinants of health, COPD management, environmental factors and objective measures of disease severity and physical performance should be considered in future studies. 


\section{Acknowledgements}

The Veterans Affairs ACQUIP was funded by VA Health Services Research and Development grants No. SDR96-002 and IIR99-376. Researcher funding: Department of Veterans Affairs
Health Services Research and Development Career Development Awards (Drs. D.H. Au and V.S. Fan); grants from the Swiss National Fund, the Société Académique Vaudoise and the Centre Hospitalier Universitaire Vaudois, Lausanne, Switzerland (Dr. P.-O. Bridevaux).

\section{References}

1 Mannino DM: COPD: epidemiology, prevalence, morbidity and mortality, and disease heterogeneity. Chest 2002;121(suppl 5):121S$126 \mathrm{~S}$.

-2 Centers for Disease Control and Prevention: Deaths from chronic obstructive pulmonary disease - United States, 2000-2005. MMWR Morb Mortal Wkly Rep 2008;57:1229-1232.

-3 Murray CJ, Lopez AD: Alternative projections of mortality and disability by cause 1990-2020: Global Burden of Disease Study. Lancet 1997;349:1498-1504.

4 Domingo-Salvany A, Lamarca R, Ferrer M, Garcia-Aymerich J, Alonso J, Felez M, Khalaf A, Marrades RM, Monso E, Serra-Batlles J, et al: Health-related quality of life and mortality in male patients with chronic obstructive pulmonary disease. Am J Respir Crit Care Med 2002;166:680-685.

5 Fan VS, Curtis JR, Tu SP, McDonell MB, Fihn SD: Using quality of life to predict hospitalization and mortality in patients with obstructive lung diseases. Chest 2002;122: 429-436.

-6 Oga T, Nishimura K, Tsukino M, Sato S, Hajiro T: Analysis of the factors related to mortality in chronic obstructive pulmonary disease: role of exercise capacity and health status. Am J Respir Crit Care Med 2003;167: 544-549.

7 Sprenkle MD, Niewoehner DE, Nelson DB, Nichol KL: The Veterans Short Form 36 questionnaire is predictive of mortality and health-care utilization in a population of veterans with a self-reported diagnosis of asthma or COPD. Chest 2004;126:81-89.

-8 Benzo R, Chang CC, Farrell MH, Kaplan R, Ries A, Martinez FJ, Wise R, Make B, Sciurba F: Physical activity, health status and risk of hospitalization in patients with severe chronic obstructive pulmonary disease. Respiration 2010;80:10-18.

-9 Matthews FE, Miller LL, Brayne C, Jagger C: Regional differences in multidimensional aspects of health: findings from the MRC cognitive function and ageing study. BMC Public Health 2006;6:90.

10 Porell FW, Miltiades HB: Regional differences in functional status among the aged. Soc Sci Med 2002;54:1181-1198.
11 Kazis LE, Miller DR, Skinner KM, Lee A, Ren XS, Clark JA, Rogers WH, Iii AS, Selim A, Linzer M, et al: Applications of methodologies of the Veterans Health Study in the VA healthcare system: conclusions and summary. J Ambul Care Manage 2006;29:182188.

$12 \mathrm{Au}$ DH, McDonell MB, Martin DC, Fihn SD: Regional variations in health status. Med Care 2001;39:879-888.

13 Ashton CM, Petersen NJ, Souchek J, Menke TJ, Yu HJ, Pietz K, Eigenbrodt ML, Barbour G, Kizer KW, Wray NP: Geographic variations in utilization rates in Veterans Affairs hospitals and clinics. N Engl J Med 1999;340: 32-39.

14 Subramanian U, Weinberger M, Eckert GJ, L'Italien GJ, Lapuerta P, Tierney W: Geographic variation in health care utilization and outcomes in veterans with acute myocardial infarction. J Gen Intern Med 2002;17: 604-611.

15 Joo MJ, Lee TA, Weiss KB: Geographic variation in chronic obstructive pulmonary disease exacerbation rates. J Gen Intern Med 2007;22:1560-1565.

16 Fihn SD, McDonell MB, Diehr P, Anderson SM, Bradley KA, Au DH, Spertus JA, Burman M, Reiber GE, Kiefe CI, et al: Effects of sustained audit/feedback on self-reported health status of primary care patients. Am J Med 2004;116:241-248.

17 Tu SP, McDonell MB, Spertus JA, Steele BG, Fihn SD: A new self-administered questionnaire to monitor health-related quality of life in patients with COPD. Ambulatory Care Quality Improvement Project (ACQUIP) Investigators. Chest 1997;112:614-622.

18 Boueri FM, Bucher-Bartelson BL, Glenn KA, Make BJ: Quality of life measured with a generic instrument (Short Form-36) improves following pulmonary rehabilitation in patients with COPD. Chest 2001;119:77-84.

19 Harper R, Brazier JE, Waterhouse JC, Walters SJ, Jones NM, Howard P: Comparison of outcome measures for patients with chronic obstructive pulmonary disease (COPD) in an outpatient setting. Thorax 1997;52:879-887.

20 Mahler DA, Mackowiak JI: Evaluation of the short-form 36-item questionnaire to measure health-related quality of life in patients with COPD. Chest 1995;107:1585-1589.
21 Ware J: Physical and Mental Health Summary Scales: A User's Manual. Boston, The Health Institute, New England Medical Center, 1994.

22 Charlson ME, Pompei P, Ales KL, MacKenzie CR: A new method of classifying prognostic comorbidity in longitudinal studies: development and validation. J Chronic Dis 1987;40:373-383.

$\checkmark 23$ Deyo RA, Cherkin DC, Ciol MA: Adapting a clinical comorbidity index for use with ICD9-CM administrative databases. J Clin Epidemiol 1992;45:613-619.

24 Groll DL, To T, Bombardier C, Wright JG: The development of a comorbidity index with physical function as the outcome. J Clin Epidemiol 2005;58:595-602.

25 Fan VS, Ramsey SD, Make BJ, Martinez FJ: Physiologic variables and functional status independently predict COPD hospitalizations and emergency department visits in patients with severe COPD. COPD 2007;4:2939.

26 Kazis LE, Miller DR, Clark J, Skinner K, Lee A, Rogers W, Spiro A 3rd, Payne S, Fincke G, Selim A, et al: Health-related quality of life in patients served by the Department of Veterans Affairs: results from the Veterans Health Study. Arch Intern Med 1998; 158: 626-632.

27 Eisner MD, Yelin EH, Trupin L, Blanc PD: The influence of chronic respiratory conditions on health status and work disability. Am J Public Health 2002;92:1506-1513.

28 Ferrer M, Alonso J, Morera J, Marrades RM, Khalaf A, Aguar MC, Plaza V, Prieto L, Anto JM: Chronic obstructive pulmonary disease stage and health-related quality of life. The Quality of Life of Chronic Obstructive Pulmonary Disease Study Group. Ann Intern Med 1997;127:1072-1079.

29 Ketelaars CA, Schlosser MA, Mostert R, Huyer Abu-Saad H, Halfens RJ, Wouters EF: Determinants of health-related quality of life in patients with chronic obstructive pulmonary disease. Thorax 1996;51:39-43.

30 Moy ML, Reilly JJ, Ries AL, Mosenifar Z, Kaplan RM, Lew R, Garshick E: Multivariate models of determinants of health-related quality of life in severe chronic obstructive pulmonary disease. J Rehabil Res Dev 2009; 46:643-654. 
-31 Lyons RA, Crome P, Monaghan S, Killalea D, Daley JA: Health status and disability among elderly people in three UK districts. Age Ageing 1997;26:203-209.

-32 Ries AL, Kaplan RM, Limberg TM, Prewitt LM: Effects of pulmonary rehabilitation on physiologic and psychosocial outcomes in patients with chronic obstructive pulmonary disease. Ann Intern Med 1995;122:823832.

33 Ries AL, Kaplan RM, Myers R, Prewitt LM: Maintenance after pulmonary rehabilitation in chronic lung disease: a randomized trial. Am J Respir Crit Care Med 2003;167:880888 .

-34 Steiner JF, Koepsell TD, Fihn SD, Inui TS: A general method of compliance assessment using centralized pharmacy records. Description and validation. Med Care 1988;26: 814-823.

-35 Incalzi RA, Bellia V, Catalano F, Scichilone N, Imperiale C, Maggi S, Rengo F: Evaluation of health outcomes in elderly patients with asthma and COPD using disease-specific and generic instruments: the Salute Respiratoria nell'Anziano (Sa.R.A.) Study. Chest 2001;120:734-742.
36 Schrier AC, Dekker FW, Kaptein AA, Dijkman JH: Quality of life in elderly patients with chronic nonspecific lung disease seen in family practice. Chest 1990;98:894-899.

37 Anderson HR, Spix C, Medina S, Schouten JP, Castellsague J, Rossi G, Zmirou D, Touloumi G, Wojtyniak B, Ponka A, et al: Air pollution and daily admissions for chronic obstructive pulmonary disease in 6 European cities: results from the APHEA project. Eur Respir J 1997;10:1064-1071.

38 Dominici F, Peng RD, Bell ML, Pham L, McDermott A, Zeger SL, Samet JM: Fine particulate air pollution and hospital admission for cardiovascular and respiratory diseases. JAMA 2006;295:1127-1134.

39 Ko FW, Tam W, Wong TW, Chan DP, Tung AH, Lai CK, Hui DS: Temporal relationship between air pollutants and hospital admissions for chronic obstructive pulmonary disease in Hong Kong. Thorax 2007;62:780785.

40 Peel JL, Tolbert PE, Klein M, Metzger KB, Flanders WD, Todd K, Mulholland JA, Ryan PB, Frumkin H: Ambient air pollution and respiratory emergency department visits. Epidemiology 2005;16:164-174.
41 Agha Z, Lofgren RP, VanRuiswyk JV, Layde PM: Are patients at Veterans Affairs medical centers sicker? A comparative analysis of health status and medical resource use. Arch Intern Med 2000;160:3252-3257.

42 Ware J: SF-36 Health Survey, Manual and Interpretation Guide, ed 1. Boston, The Health Institute, New England Medical Center, 1993.

43 Bourbeau J, Julien M, Maltais F, Rouleau M, Beaupre A, Begin R, Renzi P, Nault D, Borycki E, Schwartzman K, et al: Reduction of hospital utilization in patients with chronic obstructive pulmonary disease: a diseasespecific self-management intervention. Arch Intern Med 2003;163:585-591.

44 Fishman A, Martinez F, Naunheim K, Piantadosi S, Wise R, Ries A, Weinmann G, Wood DE: A randomized trial comparing lung-volume-reduction surgery with medical therapy for severe emphysema. N Engl J Med 2003;348:2059-2073.

45 Jones PW, Bosh TK: Quality of life changes in COPD patients treated with salmeterol. Am J Respir Crit Care Med 1997;155:12831289. 